\section{FELLOWSHIP IN VASCULAR SURGERY}

The Deborah Heart and Lung Center is currently seeking qualified applicants for a Vascular Fellow position. Please contact:

Lynn B. McGrath, MD Chairman, Dept. of Surgery

(609) 893-6611, Ext. 359

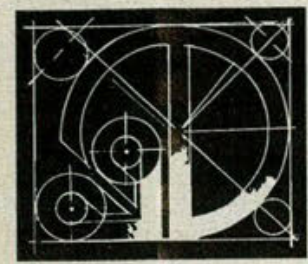

Deborah Heart and Lung Center 200 Trenton Road Browns Mills, NJ 08015

\section{ADJUNCT STAFF SURGEON}

The Department of Surgery of the Deborah Heart and Lung Center invites applications for the position of Adjunct Staff Surgeon for the Division of Cardiac Surgery.

This opportunity is appropriate for a Surgeon having completed his/her cardiac surgery training and desiring further operative experience in the setting of a busy and varied clinical practice.

Please send curriculum vitae to:

Lynn B. McGrath, MD Chairman, Dept. of Surgery

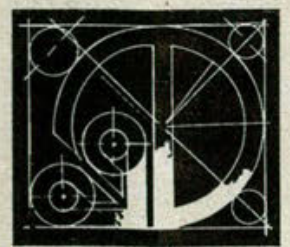

\section{Deborah Heart} and Lung Center

200 Trenton Road Browns Mills, NJ 08015

\title{
advertisers' index
}

American Osteopathic

Association

Executive Director Search

Committee, 1172

Basel Pharmaceuticals

Habitrol, 1165, Cover 3

Deborah Heart and Lung

Center, 1168, 1252

Flint Osteopathic Hospital, 1167

Glaxo Pharmaceuticals

Zinacef, 1199, 1200

Lederle Laboratories

ProStep, 1185, 1186

Eli Lilly and Company

Ceclor, 1160-1162

MedicAlert, 1178

Merck Sharp \& Dohme

Mevacor, 1173-1176

Plendil, 1213-1220,1194a,1194b
Parke-Davis

Lopid, 1192-1194

Pfizer Labs Division

Feldene, 1203, 1204

Procardia XL, 1169, 1170

Roche Laboratories

Medical Director's Page, 1207

Roerig Division, Pfizer

Incorporated

Unasyn, 1188-1190

SmithKline Beecham

Augmentin, Cover 4

Tagamet, 1183

Tyler \& Company, 1187

The Upjohn Company

Halcion, Cover 2-2

West Jersey Family Practice Residency, 1166

Wyeth-Ayerst Laboratories/ A. H. Robins Company

Micro-K, 1179, 1191 